\title{
A Novel Benzoxazole-Containing Poly(N-isopropylacrylamide) Copolymer as a Multifunctional Sensing Material $^{\mathrm{a}}$
}

\author{
Chang-Chung Yang, Yanqing Tian, Ching-Yi Chen, Alex K.-Y. Jen,* \\ Wen-Chang Chen*
}

We report a novel multifunctional material, poly( $N$-isopropylacrylamide) (PNIPAAm) containing 2-(2-hydroxyphenyl)benzoxazole (HPBO), for sensing $\mathrm{pH}$, zinc ion concentration, or temperature. By titration with zinc ions, a clear blue-shifted emission with a high quantum efficiency was detected since the zinc complex prevented the nonradiative decay pathways of the HPBO moiety. The fluorescence characteristics of the copolymer were similar at various acidic or neutral conditions. However, a large blue shift on the emission maximum was exhibited under the basic condition, due to the disruption of the ESIPT process by the phenolate anion. The LCST affected the fluorescence properties significantly at the basic condition because the incompatibility between the PNIPAAm chain and phenolated HPBO moieties resulted in aggregation formation. The present study demonstrates that the new benzoxazole-containing PINPAAm copolymer could be potentially used as multifunctional sensing material.

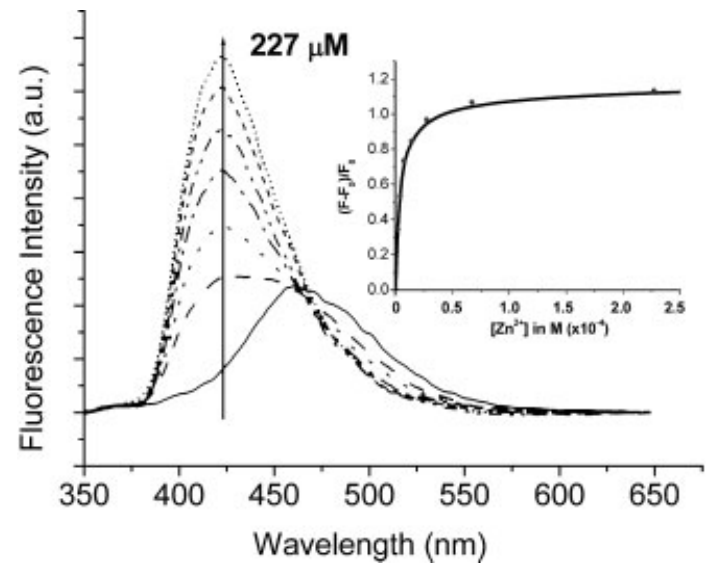

C.-C. Yang, Y. Tian, C.-Y. Chen, A. K.-Y. Jen

Materials Science and Engineering, University of Washington,

Box 352120, Seattle, WA 98195, USA

E-mail: ajen@u.washington.edu

C.-C. Yang, W.-C. Chen

Department of Chemical Engineering, National Taiwan University, Taipei 106, Taiwan

Fax: +88622362 3040; E-mail: chenwc@ntu.edu.tw

C.-C. Yang

Energy and Environmental Laboratories, Industrial Technology Research Institute, Hsinchu 310, Taiwan

W.-C. Chen

Institute of Polymer Science and Engineering, National Taiwan University, Taipei 106, Taiwan

\footnotetext{
a $[$ Supporting information for this article is available at the bottom of the article's abstract page, which can be accessed from the journal's homepage at http://www.mrc-journal.de, or from the author.
}

\section{Introduction}

The development of functional polymers as metal ion(s), temperature, sugar, oxygen, and/or DNA sensors is important and challenging for not only academic interest but also for real applications in environmental or biotechnology. ${ }^{[1,2]}$ 2-(2-Hydroxyphenyl)benzoxazole (HPBO) based functional materials can undergo excited-state intramolecular proton transfer (ESIPT, as shown in Figure 1) by the structural transformation between the enol and keto tautomers. $^{[3]}$ The ESIPT of the HPBO could result in a large Stokes shift on the fluorescence emission ranging from 100 to $500 \mathrm{~nm}$, which is of significant interest as sensing materials for metal ions or $\mathrm{pH}$. Furthermore, the HPBO moiety can also chelate with zinc ion, ${ }^{[4]}$ which is the 


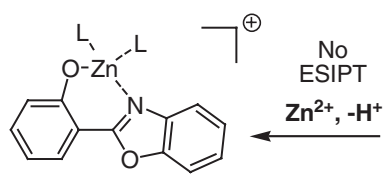

zinc complex $(X)$

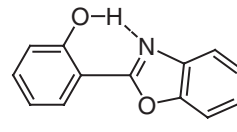

enol tautomer (E)
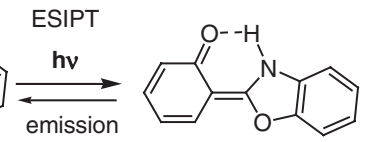

keto tautomer (K)

L: ligand or solvent

Figure 1. The excited-state intramolecular proton transfer of HPBO and its zinc complex.

second most abundant transition metal ion found in the body and may lead to neutron disorders, prostate cancer, and diabetes. ${ }^{[5]}$ During the coordination of zinc ion, the phenol group in the HPBO is deprotonated and the generated phenolate anion acts as a donor atom in the zinc complex (Figure 1). ${ }^{[4]}$ Through the complexation with zinc ion, the ESIPT process is efficiently disrupted and a blue shifted emission is detected from the zinc complex. ${ }^{[4 b, 4 c]}$ On the other hand, under basic condition, the phenol group of the HPBO moiety could be easily deprotonated to form a free phenolate anion ${ }^{[4 b, 4 c]}$ (the HPBO moiety with the free phenolate anion is called phenolated HPBO in the following text) resulting in the disruption of the ESIPT.

Polymers based on the HPBO moiety as metal ion sensors ${ }^{[4 d]}$ were previously reported. However, the water solubility and selectivity are limited in their applications in biological environments. Herein, we report a new HPBO-containing PNIPAAm copolymer as pH, zinc ion, and temperature sensors. To the best of our knowledge, it is the first time that zinc ion and $\mathrm{pH}$ sensors based on watersoluble HPBO-containing polymers are being reported. Furthermore, PNIPAAm is also a temperature-sensitive polymer with a reversible phase-transition (lower critical solution temperature, LCST) at about $32{ }^{\circ} \mathrm{C}$ in pure water. ${ }^{[6]}$ Copolymerization of NIPAAm with a fluorescent monomer could produce novel sensory materials in the body temperature range, in which the fluorescent characteristics may possibly be influenced by the microenvironmental variations due to the LCST. ${ }^{[2 f, 6 e]}$ In addition, the zinc ion and $\mathrm{pH}$ stimulated fluorescence, the temperature-stimulated emission properties of the HPBO-containing PNIPAAm are also reported.

\section{Experimental Part}

\section{Materials}

11-Bromo-1-undecanol, chloromethyl methyl ether, 2,4-dihydroxybenzaldehyde, 2-hydroxyaniline, 1-(3-dimethylaminopropyl)-3-ethylcarbodiimide hydrochloride (EDC), and 2,2'azoisobutyronitrile (AIBN) were purchased from Aldrich and used as received. NIPAAm was purified by twice repeated recrystallization from hexane. Tetrahydrofuran (THF) was distillated from sodium/benzophenone under nitrogen. 4-(11- Hydroxyundecyl)-2hydroxylbenzaldehyde (1) was prepared according to a known procedure. ${ }^{[7]}$ All the reactions were conducted using oven-dried glassware under a nitrogen atmosphere and were stirred magnetically. The Briton-Robinson buffer ${ }^{[8]}$ was used.

\section{Synthesis}

The precursors of 2-4; the new monomer 2-\{2-hydroxy-4-[11-(acryloxy)undecyloxy]-

phenyl\}benzoxazole (5), and the HPBO-containing PNIPAAm copolymer (6) were synthesized according to Scheme 1 and detailed as below.

2-(Methoxymethoxy)-4-[(11-methoxymethoxy)undecyloxy] benzaldehyde (2)

$10 \mathrm{~g}$ (32 mmol) of compound 1 was dissolved into $100 \mathrm{~mL}$ of dry methylene chloride and $20 \mathrm{~mL}$ of isopropylamine (115 mmol). At $0-5{ }^{\circ} \mathrm{C}, 6 \mathrm{~mL}$ (79 mmol) of chloromethyl methyl ether was added. And then, the mixture was stirred at room temperature for overnight. After washing with $5 \% \mathrm{NaHCO}_{3}$ and brine, dried over $\mathrm{Na}_{2} \mathrm{SO}_{4}$, the solvent was removed under vacuum. $12.5 \mathrm{~g}$ of oil (yield 98\%) was obtained and used for next step without further purification.

${ }^{1} \mathrm{HNMR}\left(\mathrm{CDCl}_{3}, 300 \mathrm{MHz}\right): \delta=10.4\left(\mathrm{~s}, \mathrm{H}^{1}, \mathrm{CHO}\right), 7.85\left(\mathrm{~d}, \mathrm{H}^{1}\right.$, phenyl), 6.75 (s, $\mathrm{H}^{1}$, phenyl), 6, $64\left(\mathrm{~d}, \mathrm{H}^{1}\right.$, phenyl), 5.34 (s, $\mathrm{H}^{2}, \mathrm{CH}_{3} \mathrm{OCH} \mathrm{CH}_{2} \mathrm{OPh}$ ), 4.62 (s, $\left.\mathrm{H}^{2}, \mathrm{CH}_{3} \mathrm{OCH}_{2} \mathrm{OCH}_{2}\right), 4.04$ (t, $\mathrm{H}^{2}$, $\mathrm{PhOCH}_{2} \mathrm{CH}_{2}$ ), 3.56 (s, $\left.\mathrm{H}^{3}, \mathrm{CH}_{3} \mathrm{O}\right), 3.52\left(\mathrm{t}, \overline{\mathrm{H}^{2}, \mathrm{CH}_{3} \mathrm{OCH}_{2}} \underline{\mathrm{OCH}_{2}}\right), 3.38$ (s, $\left.\mathrm{H}^{3}, \underline{\mathrm{CH}_{3} \mathrm{OCH}} \mathrm{H}_{2} \mathrm{OPh}\right), 1.8-1.2\left[\mathrm{~m}, \mathrm{H}^{18},\left(\mathrm{CH}_{2}\right)_{9}\right]$.

2-\{2-(Methoxymethoxy)-4-[(11-methoxymethoxy) undecyloxy]phenyl\}benzoxazole (3)

$12.5 \mathrm{~g}$ of the compound $\mathbf{2}$ (31 mmol), $3.4 \mathrm{~g}$ of 2-hydroxyaniline (31 mmol) in $200 \mathrm{~mL}$ of benzene was refluxed azeotropically for $15 \mathrm{~h}$. Then $20 \mathrm{~g}$ of $\mathrm{BaMnO}_{4}$ was added into the mixture and kept at refluxing for $24 \mathrm{~h}$. The inorganic salt was removed through the filtration of Celite. Then the organic solvent was removed under vacuum, and passed through a silica gel column with methylene chloride/ethyl acetate as eluent. $8.0 \mathrm{~g}$ of a white powder was obtained in 54\% yield.

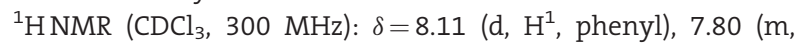
$\mathrm{H}^{1}$, phenyl), 7.57 ( $\mathrm{m}, \mathrm{H}^{1}$, phenyl), 7.35 ( $\mathrm{m}, \mathrm{H}^{2}$, phenyl), $6.84(\mathrm{~d}$, $\mathrm{H}^{1}$, phenyl), $6.72\left(\mathrm{dd}, 1 \mathrm{H}\right.$, phenyl), $5.38\left(\mathrm{~s}, \mathrm{H}^{2}, \mathrm{CH}_{3} \mathrm{OCH} \mathrm{CH}_{2} \mathrm{OPh}\right)$, $4.62\left(\mathrm{~s}, \mathrm{H}^{2}, \mathrm{CH}_{3} \mathrm{OCH}_{2} \mathrm{OCH}_{2}\right), 4.04\left(\mathrm{t}, \mathrm{H}^{2}, \mathrm{PhOCH}_{2} \mathrm{CH}_{2}\right), \quad 3.56$ $\left(\mathrm{s}, \mathrm{H}^{3}, \mathrm{CH}_{3} \mathrm{O}\right), 3.52\left(\mathrm{t}, \overline{\mathrm{H}^{2}}, \mathrm{CH}_{3} \mathrm{OCH}_{2} \mathrm{OCH}_{2}\right), 3.38\left(\mathrm{~s}, \mathrm{H}^{3}, \underline{\mathrm{CH}_{3}} \mathrm{OCH}_{2} \mathrm{Oph}\right)$, $1.8-1.2\left[\mathrm{~m}, \mathrm{H}^{18},\left(\mathrm{CH}_{2}\right)_{9}\right]$.

\section{2-[2-Hydroxy-4-(11-hydroxyundecyloxy)}

phenyl]benzoxazole (4)

$300 \mathrm{mg}$ of compound 3 (0.62 mmol) was dissolved into $15 \mathrm{~mL}$ methanol. $300 \mathrm{mg}$ of $p$-toluene sulfonic acid was added into the solution, and then the mixture was stirred at room temperature for $2 \mathrm{~d}$. After removing the solvent, the remaining material was dissolved in $20 \mathrm{~mL}$ of diethyl ether, and then the ether was washed with $5 \% \mathrm{NaHCO}_{3}$, and dried over $\mathrm{Na}_{2} \mathrm{SO}_{4}$. After column chromatography with methylene chloride/methanol (20:1 by volume), $200 \mathrm{mg}$ of white powder was obtained in $81 \%$ yield. 

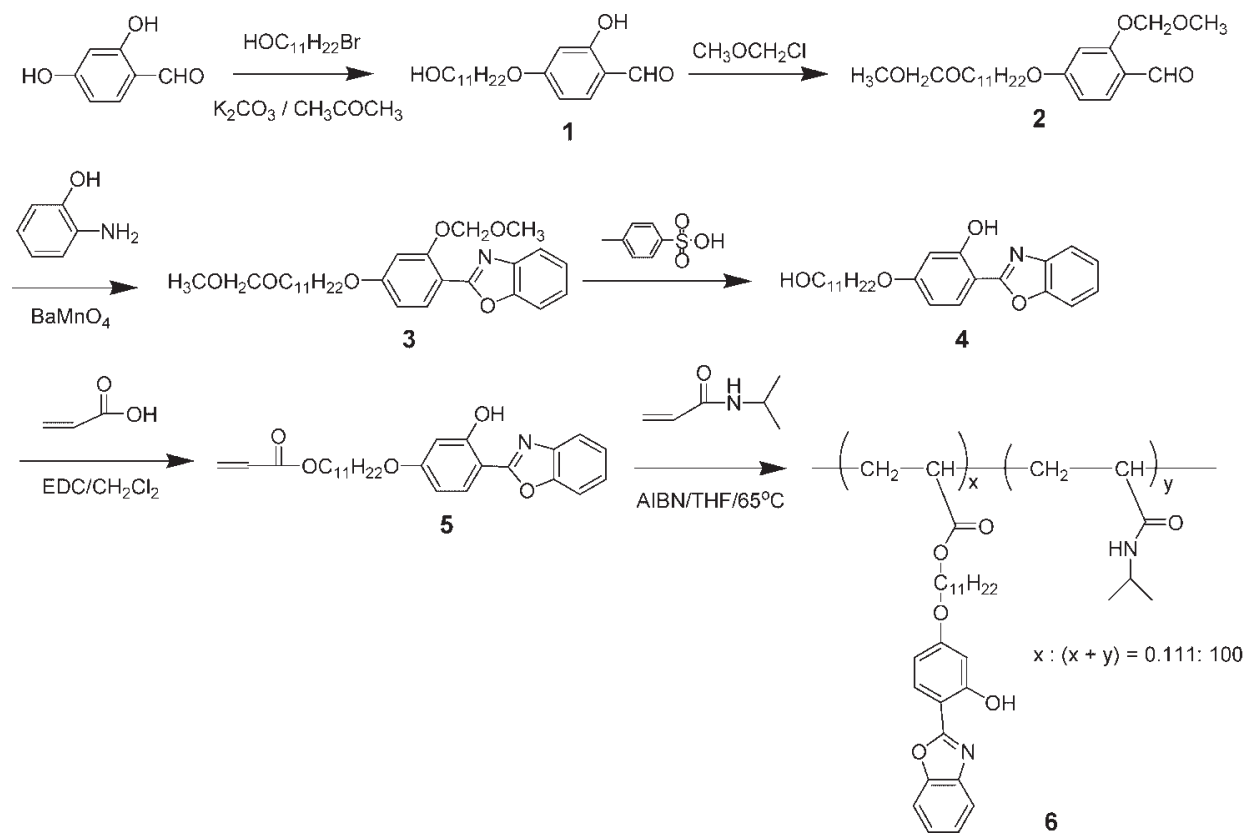

Scheme 1. Synthesis of the poly( $\mathrm{N}$-isopropylacrylamide) (PNIPAAm) copolymer containing 2-(2hydroxyphenyl)benzoxazole (HPBO) (6).

${ }^{1} \mathrm{HNMR} \quad\left(\mathrm{CDCl}_{3}, \quad 300 \mathrm{MHz}\right): \delta=11.60$ (s, $\mathrm{H}^{1}$, phenyl-OH), 7.91 (d, $\mathrm{H}^{1}$, phenyl), $7.70\left(\mathrm{~m}, \mathrm{H}^{1}\right.$, phenyl), $7.59\left(\mathrm{~m}, \mathrm{H}^{1}\right.$, phenyl), $7.39\left(\mathrm{~m}, \mathrm{H}^{2}\right.$, phenyl), $6.59\left(\mathrm{~m}, \mathrm{H}^{2}\right.$, phenyl), $4.04\left(\mathrm{t}, \mathrm{H}^{2}, \mathrm{PhOCH}_{2}\right)$, $3.67\left(\mathrm{t}, \mathrm{H}^{2}, \mathrm{CH}_{2} \mathrm{OH}\right), 1.8-1.2\left[\mathrm{~m}, \mathrm{H}^{18},\left(\mathrm{CH}_{2}\right)_{9}\right]$.

2-\{2-Hydroxy-4-[11-(acryloxy)undecyloxy]phenyl\} benzoxazole (5)

$1.0 \mathrm{~g}$ of compound 4 (2.5 mmol), $180 \mathrm{mg}$ of acrylic acid (2.5 mmol), EDC (600 mg, $3 \mathrm{mmol}$ ), and 4-dimethylaminopyridine (30 mg) were suspended in $10 \mathrm{~mL}$ of dry methylene chloride. The mixture was stirred at room temperature for $24 \mathrm{~h}$. After removing the solvent, the mixture was purified through column chromatography with hexane/ethyl acetate ( $5: 1$ by volume) to get $500 \mathrm{mg}$ of the monomer (5) in $44 \%$ yield. The ${ }^{1} \mathrm{H} N M R$ spectrum is shown in Figure S2.

${ }^{1} \mathrm{HNMR} \quad\left(\mathrm{CDCl}_{3}, 300 \mathrm{MHz}\right): \delta=11.60$ (s, $\mathrm{H}^{1}$, phenyl-OH), 7.91 (d, $\mathrm{H}^{1}$, phenyl), 7.70 ( $\mathrm{m}, \mathrm{H}^{1}$, phenyl), 7.59 (m, $\mathrm{H}^{1}$, phenyl), $7.39\left(\mathrm{~m}, \mathrm{H}^{2}\right.$, phenyl), $6.59\left(\mathrm{~m}, \mathrm{H}^{2}\right.$, phenyl), $6.46\left(\mathrm{~d}, \mathrm{H}^{1}, \mathrm{CH}_{2}=\right)$, $6.10\left(\mathrm{~m}, \mathrm{H}^{1}, \mathrm{CH}\right), 5.82\left(\mathrm{~d}, \mathrm{H}^{1}, \mathrm{CH}_{2}=\right), 4.16\left(\mathrm{t}, \mathrm{H}^{2}, \mathrm{CH}_{2} \mathrm{OCO}\right)$, $4.0\left(\mathrm{t}, \mathrm{H}^{2}, \mathrm{CH}_{2} \mathrm{OPh}\right), 1.8-1.2\left[\mathrm{~m}, \mathrm{H}^{18},\left(\mathrm{CH}_{2}\right)_{9}\right]$.

Mass: calcd. for $\mathrm{C}_{27} \mathrm{H}_{33} \mathrm{NO}_{5}$ 451.6; found (EI): 451.5 .

\section{HPBO-containing PNIPAAm Copolymer (6)}

In order to not affect the LCST transition temperature of the PNIPAAm copolymer, the feed molar fraction of the HPBO unit to NIPAAm was set as low as $0.125 \% .{ }^{[2 f, 9]} 10.0 \mathrm{mg}$ of monomer $5(0.021 \mathrm{mmol}), 1.91 \mathrm{~g}$ of NIPAAm $(16.9 \mathrm{mmol})$, and $14.5 \mathrm{mg}$ of AIBN $(0.088 \mathrm{mmol})$ were added into $7 \mathrm{~mL}$ of THF solution and degassed by the freeze-pump-thaw method. The polymerization reaction was carried out in a Schlenk tube under nitrogen at $65^{\circ} \mathrm{C}$. The reaction was allowed to proceed for $2 \mathrm{~d}$ for complete polymerization. A small amount of the polymerization mixture was taken for the determination of the conversion. The ${ }^{1} \mathrm{H}$ NMR result showed that the conversion was greater than 95\%. The reaction mixture was poured into diethyl ether and filtrated. The obtained polymer 6 was purified by reprecipitation from THF into diethyl ether to get $1.69 \mathrm{~g}$ of final product with a yield of $88 \% . \bar{M}_{\mathrm{w}}=39500$, $\bar{M}_{\mathrm{w}} / \bar{M}_{\mathrm{n}}=2.96$. The molar percentage of the HPBO unit in polymer 6 was determined to be $0.111 \%$ by the concentration standard curve through the UV-vis absorption spectra.

\section{Characterizations}

${ }^{1} \mathrm{H} \quad \mathrm{NMR}$ spectra were measured with a Bruker 300 instrument spectrometer operating at $300 \mathrm{MHz}$ with the internal standard tetramethylsilane as a reference for chemical shifts. The molecular weight of the polymers were determined with a Waters 1515 gel permeation chromatograph coupled with UV and refractive-index detectors, with reference to a series of standard polystyrenes for calibration with dimethylformamide as an eluent. UV-vis absorption spectra were recorded with a Hewlett Packard 8452A diode-array UV-vis spectrophotometer. Fluorescence spectra were measured using a Perkin-Elmer LS-50B Luminescence Spectrophotometer. For fluorescence titrations, a sample solution in a quartz cuvette was excited at the isosbestic points determined by UV titrations. Polymer concentration in aqueous solution used in this study is $\mathrm{mg} \cdot \mathrm{mL}^{-1}$ corresponding to the HPBO concentration of $9.8 \times 10^{-6} \mathrm{M}$.

\section{Results and Discussion}

Though the monomer $\mathbf{5}$ is completely insoluble in water, the polymer 6 has a good solubility $\left(>10 \mathrm{mg} \cdot \mathrm{mL}^{-1}\right)$ in aqueous solution after incorporating the PNIPAAm moiety. The LCST $\left(32^{\circ} \mathrm{C}\right)$ of the polymer 6 was same as that of pure PNIPAAm due to the low molar ratio $(0.111 \%)$ of the HPBO moiety in the copolymer, as shown in Figure S3 (see Supporting Information). The photoluminescence quantum yield of polymer 6 in aqueous solution was 0.15 as determined by using 9,10-diphenylanthracene in cyclohexane as a standard. ${ }^{[10]}$ The low quantum yield is normal for the HPBO-containing materials, which is possibly due to the low HPBO content, significant nonradiative decay from the ESIPT or torsion angle between the phenyl ring and benzoxazole moiety. ${ }^{[3,4 b, 4 c]}$ 

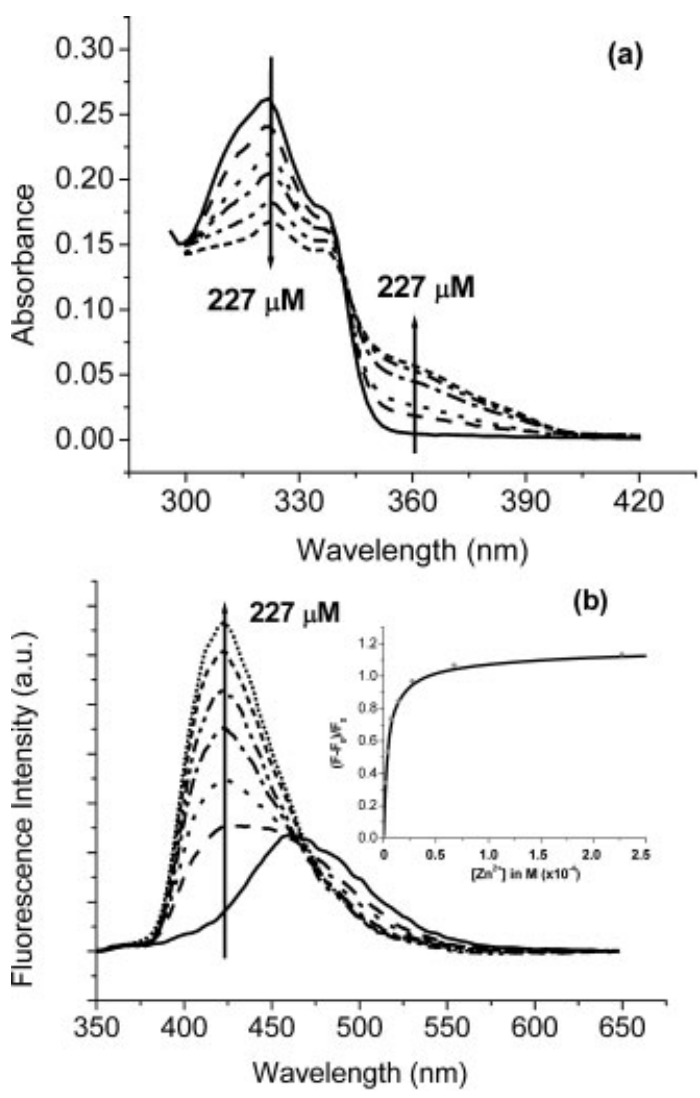

Figure 2. Variation of the UV-Vis absorption (a) and fluorescence (b) spectra of polymer 6 in aqueous solution along with the titration of zinc acetate. The excitation wavelength for $(b)$ is at $341 \mathrm{~nm}$ of the isosbestic point. The inset figure of (b) gives the zinc concentration dependent fluorescence enhancement during the titration process. $F_{\mathrm{o}}$ is the integration emission intensity before titration, $F$ is the integration emission intensity after titration.

Figure 2(a) and 2(b) show the UV-vis and fluorescence spectra of polymer $\mathbf{6}$ in aqueous solution with a concentration of $1 \mathrm{mg} \cdot \mathrm{mL}^{-1}$ titrated using zinc ion. With the titration of zinc ion, the absorption maximum at $321 \mathrm{~nm}$ decreased and a broad band from $\approx 350$ to $400 \mathrm{~nm}$ increased progressively. The absorption band at the longer wavelength indicated the formation of the zinc complex, as shown in Figure 1. The observation of an isosbestic point at $341 \mathrm{~nm}$ in Figure 2(a) indicates a simple complex formation process. ${ }^{[4 a, 4 b]}$ During the titration process, clear blue-shifted emissions were detected and suggested the interruption of the ESIPT process by the zinc complexation, as exhibited in Figure 1. Because the zinc complex prevents the nonradiative decay pathways of the HPBO moiety, the fluorescence quantum yield at zinc equilibrium state enhanced to 0.34 .

Curve fitting of the fluorescence intensity according to the Benesi-Hildebrand plot ${ }^{[11]}$ supported the formation of a 1:1 complex of HPBO moiety in polymer 6 with zinc ions. Its binding constant $(K)$ is estimated to be $1.87 \times 10^{5} \mathrm{M}^{-1}$.
The calculated binding constant of polymer 6 is in between the reported $K$ values of $2.0 \times 10^{6} \mathrm{M}^{-1}$ (in methanol) ${ }^{[4 \mathrm{c}]}$ and $8.5 \times 10^{3} \mathrm{M}^{-1}$ (in water) ${ }^{[4 \mathrm{~b}]}$ using various HPBO derivatives. However, the fluorescence enhancement of the zinc complex of polymer 6 [1.25-fold, inset figure of Figure 2(b)] is much smaller than the reported values (6-50-folds) using other low molecular weight HPBO materials. ${ }^{[4]}$ It is probably only $0.111 \mathrm{~mol}-\%$ of fluorescence HPBO moiety incorporated into the polymer 6 .

The effects of various metal ions on the emissions of polymer 6 on the fluorescence intensity at their equilibrium states are summarized in Figure S4 of the Supporting Information. Polymer 6 recognizes zinc ions, thus bringing about a large enhancement of fluorescence, which is necessary and important for an effective chemical sensor. This shows its good selectivity for zinc ions. Other physiologically important ions, such as $\mathrm{Mg}^{2+}, \mathrm{Ca}^{2+}, \mathrm{Na}^{+}$, and $\mathrm{K}^{+}$, gave much less enhancement in fluorescence emissions. Several heavy metal ions $\left(\mathrm{Fe}^{3+}, \mathrm{Cu}^{2+}\right.$, and $\left.\mathrm{Ni}^{2+}\right)$ quenched the fluorescence. Similar quenching effect of HPBO molecules by heavy metal ions was reported by Iwata et al. ${ }^{[4 c]}$

The effect of $\mathrm{pH}$ on the fluorescence spectra along with absorption spectra was investigated and shown in Figure 3. The fluorescence intensity of polymer 6 under acidic conditions is almost the same as that in neutral solutions, but it is quite sensitive to basic conditions [Figure 3(b)], especially in the $\mathrm{pH}$ range of 9-11. It is notable that the absorbance at longer wavelength $(\approx 360 \mathrm{~nm})$ increases [Figure 3(a)] and the emission maximum shifts towards blue under basic conditions [Figure 3(b)]. The fluorescence quantum yield was determined to be 0.49 at $\mathrm{pH}$ of 11.6. In the basic aqueous solution, the phenolate anion coming from the intermolecular proton transfer to the hydroxyl anion thus disrupted the ESIPT process ${ }^{[3 c]}$ similar to the case of the zinc cation. The formation of phenolate anion under basic conditions explains the above variation of absorption and fluorescence.

The temperature-responsive fluorescence properties using the polymer 6 at pH 2.0, 7.0, and 11.6 and at the zinc equilibrium condition were investigated. Clear fluorescence spectra and intensity changes were observed under basic condition [Figure 3(c)] when the temperature approaches $32^{\circ} \mathrm{C}$. The emission has no further change when temperature is higher than $40^{\circ} \mathrm{C}$. When the temperature was higher than $32^{\circ} \mathrm{C}$, the emission peak at $425 \mathrm{~nm}$ decreased and a new peak centered at $500 \mathrm{~nm}$, possibly due to the aggregation of the free phenolated HPBO, was observed. However, there is no change of fluorescence intensity with varying temperature (in the range of $28-50^{\circ} \mathrm{C}$ ) for polymer 6 at $\mathrm{pH}=2.0$ or 7.0 , and the results for the equilibrium zinc aqueous solution is shown in Figure S5 and S6. These observations indicate that the 


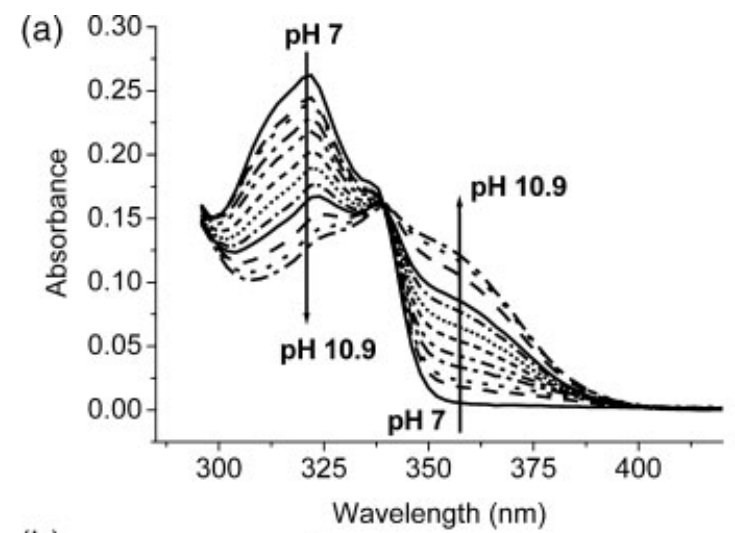

(b)
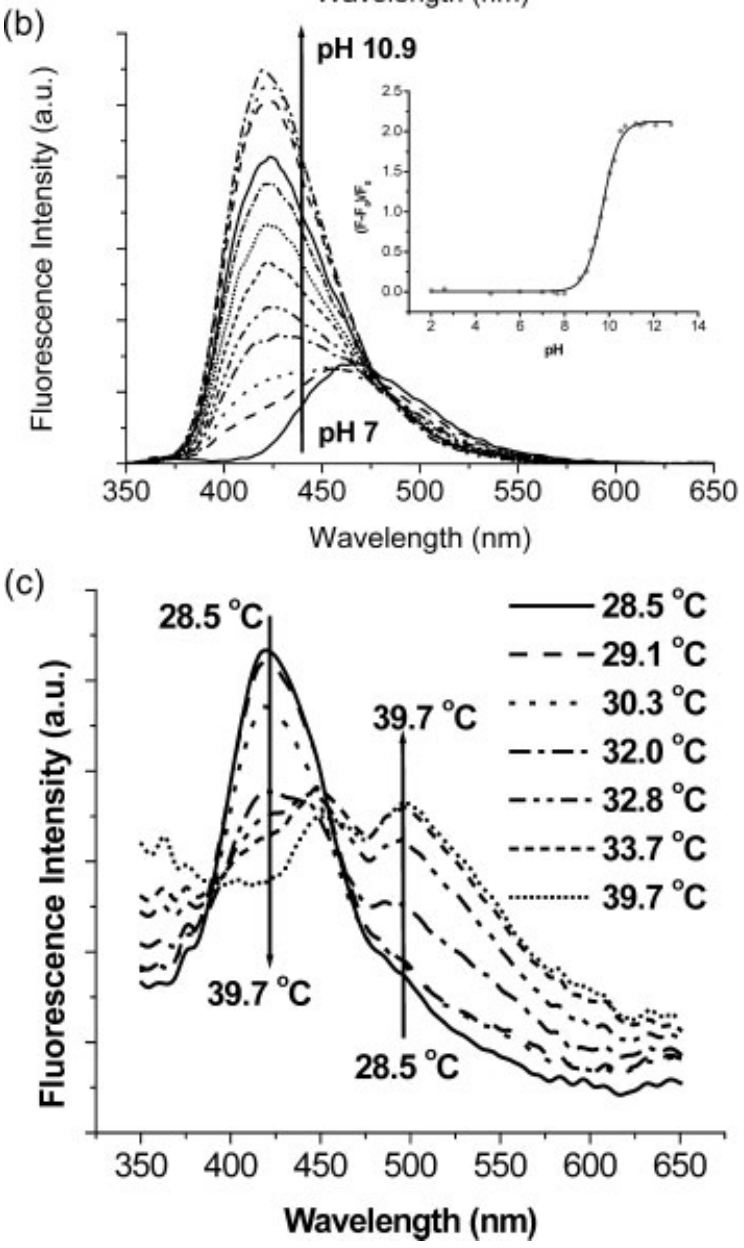

Figure 3. Variation on the fluorescence characteristics of polymer 6 with $\mathrm{pH}$ and temperature. The UV-Vis absorption spectra (a), fluorescence spectra (b) and fluorescence enhancements [inset figure of (b)] of polymer 6 in aqueous solution at various $\mathrm{pH}$ values. (c) The fluorescence spectra variation of polymer 6 along with temperature from 28.4 to $39.7^{\circ} \mathrm{C}$ at $\mathrm{pH}=11.6$. The excitation wavelength for Figure 2(b) and 2(c) is $341 \mathrm{~nm}$ at the isosbestic point.

HPBO itself and the HPBO-zinc complex are not sensitive to the change from hydrophilic and hydrophobic environments at the LCST. But the phenolated HPBO is sensitive to the microenvironmental condition. At a temperature higher than the LCST, the PNIPAAm chain becomes hydrophobic and is significantly incompatible to the hydrophilic phenolated HPBO. Such an environmental change forces the phenolated HPBO moieties in aqueous solution to form significant aggregations and results in the red-shifted fluorescence.

\section{Conclusion}

A new HPBO-containing poly( $N$-isopropylacrylamide) was developed for multifunctional sensing materials. It was demonstrated that the polymer was a selective zinc ion sensor in aqueous solution since the zinc complex prevented the nonradiative decay pathways of the HPBO moiety. Besides, a large blue shift on the emission maximum under the basic condition was exhibited since the phenolate anion disrupted the ESIPT process. The LCST transition temperature affected the fluorescence properties significantly under basic conditions due to the incompatibility between the PNIPAAm chain and the phenolated HPBO moieties. The present study demonstrates that the new benzoxazole-containing PINPAAm copolymer can be potentially used as multisensory functional materials.

Acknowledgements: We thank the National Science Council (NSC) and Ministry of Education (MOE) of Taiwan for financial supports of this work. C. C. Yang thanks for the NSC fellowship to visit Professor Alex Jen's research group for a year.

Received: December 12, 2006; Revised: January 24, 2007; Accepted: January 31, 2007; DOI: 10.1002/marc.200600869

Keywords: benzoxazole; fluorescence; PNIPAAm; stimulisensitive polymers; zinc

[1] [1a] D. T. McQuade, A. E. Pullen, T. M. Swager, Chem. Rev. 2000, 100, 2537; [1b] R. Yerushalmi, A. Scherz, M. E. Van der Boom, H. B. Krratz, J. Mater. Chem. , 15, 4480.

[2] [2a] X. H. Zhou, J. C. Yan, J. Pei, Macromolecules. 2004, 37, 7078; [2b] L. Chen, D. W. McBranch, H. Wang, R. Helgeson, F. Wudl, D. G. Whitten, Proc. Natl. Acad. Sci. USA 1999, 96, 12287; [2c] D. L. Wang, X. Gong, P. S. Heeger, F. Rininsland, G. C. Bazan, A. J. Heeger, Proc. Natl. Acad. Sci. USA 2002, 99, 49; [2d] F. Le Floch, H. A. Ho, P. Harding-Lepage, M. Bedard, R. Neagu-Plesu, M. Leclerc, Adv. Mater. 2005, 17, 1251; [2e] F. He, L. Tang, M. H. Yu, F. D. Feng, L. L. An, H. Sun, S. Wang, Y. L. Li, D. B. Zhu, G. C. Bazan, J. Am. Chem. Soc. 2006, 128, 6764; [2f] S. Uchiyam, N. Kawai, A. P. de Silva, K. Iwai, J. Am. Chem. Soc. 2004, 126, 3032.

[3] [3a] V. Kozich, J. Dreyer, A. Vodchits, W. Werncke, Chem. Phys. Lett. 2005, 415, 121; [3b] M. Ikegami, T. Arai, Chem. Lett. 2000, 996; [3c] K. Das, N. Sarkar, A. K. Ghosh, D. Majumdar, D. N. Nath, K. Bhattacharyya, J. Phys. Chem. 1994, 98, 9126; [3d] O. K. Abou-Zied, R. Jimenez, E. H. Z. Thompson, D. P. Millar, F. E. Romesberg, J. Phys. Chem. A 2002, 106, 3665; 
[3e] J. Seo, S. H. Kim, S. Y. Park, J. Am. Chem. Soc. 2004, 126, 11154; [3f] N. P. Ernsting, S. A. Kovalenko, T. Senyushkina, J. Saam, V. Farztdinov, J. Phys. Chem. A 2001, 105, 3443; [3g] C. A. S. Potter, R. G. Brown, Chem. Phys. Lett. 1988, 153, 7; [3h] J. K. Lee, H. J. Kim, T. H. Kim, C. H. Lee, W. H. Park, J. Kim, T. S. Lee, Macromolecules. 2005, 38, 9427; [3I] R. Tangirala, E. Baer, A. Hitner, C. Weder, Adv. Funct. Mater. 2004, 14, 595.

[4] [4a] M. Taki, J. L. Wolford, T. V. O'Halloran, J. Am. Chem. Soc. 2004, 126, 712; [4b] M. M. Henary, C. J. Fahrni, J. Phys. Chem. A 2002, 106, 5210; [4c] K. Tanaka, T. Kumagi, H. Aoki, M. Deguchi, S. Iwata, J. Org. Chem. 2001, 66, 7328; [4d] J. K. Lee, T. S. Lee, J. Polym. Sci. A: Polym. Chem. 2005, 43, 1397.

[5] [5a] M. B. Sorensen, M. Stoltenberg, S. Juhl, G. Danscher, E. Ernst, Prostate. 1997, 31, 125; [5b] K. R. Gee, Z. L. Zhou, W. J. Qian, R. Kennedy, J. Am. Chem. Soc. 2002, 124, 776; [5c] C. J. Frederickson, S. W. Suh, D. Silva, R. B. Thompson, J. Nutr. 2000, 130, 1471S; [5d] A. R. Kay, J. Neurosci. 2003, 23, 6847.
[6] [6a] M. Heskins, J. E. Guillet, J. Macromol. Sci. A 1968, 2, 1441; [6b] G. Masci, L. Giacomelli, V. Crescenzi, Macromol. Rapid Commun. 2004, 25, 559; [6c] M. H. Stenzel, L. Zheng, W. T. S. Huck, Macromol. Rapid Commun. 2006, 27, 1121; [6d] C. Zheng, W. D. He, W. J. Liu, J. Li, J. F. Li, Macromol. Rapid Commun. 2006, 27, 1229; [6e] C. C. Yang, Y. Q. Tian, A. K.-Y. Jen, W. C. Chen, J. Polym. Sci. Polym. Chem. 2006, 44, 5495.

[7] Y. O. Tian, E. Akiyama, Y. Nagase, A. Kanazawa, O. Tsutsumi, T. Ikeda, J. Mater. Chem. 2004, 14, 3524.

[8] J. Heyrovsky, P. Zuman, "Practical Polarography", Academic Press, New York 1968.

[9] [9a] K. Iwai, N. Matsumoto, M. Niki, M. Yamamoto, Mol. Cryst. Liq. Cryst. 1998, 315, 53; [9b] C. K. Chee, S. Rimmer, D. A. Shaw, I. Soutar, L. Swanson, Macromolecules 2001, 34, 7544.

[10] S. Hamai, F. Hirayama, J. Phys. Chem. 1983, 87, 83.

[11] [11a] H. A. Benesi, J. H. Hildebrand, J. Am. Chem. Soc. 1949, 71, 2703; [11b] S. Fery-Forgues, M.-T. Le Bris, J.-P. Guetté, B. Valeur, J. Phys. Chem. 1988, 92, 6233; [11c] R. Varghese, S. J. George, A. Ajayaghosh, Chem. Commun. 2005, 593. 